Article

\title{
Insights into Xylan Degradation and Haloalkaline Adaptation through Whole-Genome Analysis of Alkalitalea saponilacus, an Anaerobic Haloalkaliphilic Bacterium Capable of Secreting Novel Halostable Xylanase
}

\author{
Ziya Liao ${ }^{1}$, Mark Holtzapple ${ }^{2}$, Yanchun Yan ${ }^{1}$, Haisheng Wang ${ }^{1}$, Jun $\mathrm{Li}^{3}$ and Baisuo Zhao ${ }^{1,3, *}$ \\ 1 Graduate School, Chinese Academy of Agricultural Sciences, Beijing 100081, China; ziyaliao@163.com (Z.L.); \\ yanyanchun@caas.cn (Y.Y.); wanghaisheng@caas.cn (H.W.) \\ 2 Department of Chemical Engineering, Texas A\&M University, College Station, TX 77843, USA; \\ m-holtzapple@mail.che.tamu.edu \\ 3 Institute of Agricultural Resources and Regional Planning, Chinese Academy of Agricultural Sciences, \\ Beijing 100081, China; junli01@caas.cn \\ * Correspondence: bszhao@live.com
}

Received: 30 October 2018; Accepted: 13 December 2018; Published: 20 December 2018

\begin{abstract}
The obligately anaerobic haloalkaliphilic bacterium Alkalitalea saponilacus can use xylan as the sole carbon source and produce propionate as the main fermentation product. Using mixed carbon sources of $0.4 \%(w / v)$ sucrose and $0.1 \%(w / v)$ birch xylan, xylanase production from $A$. saponilacus was 3.2-fold greater than that of individual carbon sources of $0.5 \%(w / v)$ sucrose or $0.5 \%(w / v)$ birch xylan. The xylanse is halostable and exhibits optimal activity over a broad salt concentration $(2-6 \% \mathrm{NaCl})$. Its activity increased approximately 1.16 -fold by adding $0.2 \%(v / v)$ Tween 20 . To understand the potential genetic mechanisms of xylan degradation and molecular adaptation to saline-alkali extremes, the complete genome sequence of $A$. saponilacus was performed with the pacBio single-molecule real-time (SMRT) and Illumina Misseq platforms. The genome contained one chromosome with a total size of 4,775,573 bps, and a G+C genomic content of $39.27 \%$. Ten genes relating to the pathway for complete xylan degradation were systematically identified. Furthermore, various genes were predicted to be involved in isosmotic cytoplasm via the "compatible-solutes strategy" and cytoplasmic $\mathrm{pH}$ homeostasis though the "influx of hydrogen ions". The halostable xylanase from A. saponilacus and its genomic sequence information provide some insight for potential applications in industry under double extreme conditions.
\end{abstract}

Keywords: Genome Sequencing; Haloalkaliphile; Xylanase; Alkalitalea saponilacus

\section{Introduction}

Haloalkaliphiles are extremophilic microorganisms that grow optimally above $0.5 \mathrm{~mol} \cdot \mathrm{L}^{-1}$ salinity $(\mathrm{NaCl})$ and above $\mathrm{pH} 9.0$ (sodium carbonate/sodium bicarbonate) [1,2]. They are naturally found in saline-alkaline environments such as soda lakes and soda deserts in various dry steppes and semi-desert areas around the world. They also are found in human industrial processes, such as those involving mineral ore, petroleum refining, pulp and paper, textile preparation, leather tanneries, food and potato processing units, lime kilns, and detergent manufacture, all of which generate effluents containing $\mathrm{NaOH}, \mathrm{Ca}(\mathrm{OH})_{2}$, etc. $[1,3,4]$. Over the last three decades, there has been increased interest in exploring haloalkaliphiles as a precious resource that produces stable unique exo-enzymes and organic compounds with potential applications in various industrial processes $[1,5,6]$. However, to date, 
our knowledge of anaerobic haloalkaliphiles associated with exploitable enzymology and genetic adaptations is still limited. The genome sequences of haloalkaliphiles may enable many new and potentially transformative biotechnological efforts by providing genetic information to meet rapidly growing industrial demands.

The obligately anaerobic haloalkaliphilic xylanolytic bacterium Alkalitalea saponilacus SC/BZ-SP2 ${ }^{\mathrm{T}}$, grows optimally at $0.44-0.69 \mathrm{~mol} \cdot \mathrm{L}^{-1} \mathrm{Na}^{+}$(equivalent to $2.6-4.0 \% \mathrm{NaCl}$ ) and $\mathrm{pH}$ 9.7. It was retrieved from a meromictic soda lake [7]. This microorganism is classified as a species in genus Alkalitalea, family Marinilabiliaceae, class Bacteroidia, order Bacteroidetes. The haloalkaliphile A. saponilacus is the first identified anaerobic bacterium that uses xylan as the sole carbon and energy source, and simultaneously produces propionic acid as the major product. If this xylanase is excreted into highly saline-alkaline surroundings and is easily recovered, perhaps it can be applied in industry, such as the biobleaching of wood pulp. This may be the first report about the complete genome sequence of $A$. saponilacus, which could be used by industry in the future.

\section{Materials and Methods}

\subsection{Concentration and Characterization of the Xylanase}

To achieve more in-depth understanding of the xylanase characteristics, A. saponilacus SC/BZ-SP2 ${ }^{\mathrm{T}}$ was optimally grown using birch xylan, sucrose, maltose, glucose, and cellobiose as sole carbon sources as described previously by Zhao and Chen [7]. The bacterial culture $(20 \mathrm{~mL})$ was mildly ultra-sonicated in an ice bath for $10 \mathrm{~min}$ with 3-s intervals while emitting $200 \mathrm{~W}$ (Branson digital sonifier 250, Branson Ultrasonics, Danbury, CT, USA). For crude concentration, the xylanse suspended in culture media was precipitated using a $40 \%$ saturated solution of ammonium sulfate and centrifuged for $20 \mathrm{~min}$ at $9425 \times g$ (i.e., $10,000 \mathrm{rpm})$ at $4{ }^{\circ} \mathrm{C}$.

Xylanase activity was measured using xylose as the standard with the modified 3, 5-dinitrosalicylic acid colorimetric method (DNS method) [8]. One unit (1 U) of purified xylanase activity was defined as the amount of enzyme that released $1 \mu \mathrm{mol}$ of xylose equivalent per min under the assay conditions. The relative xylanase activity is defined as the percentage of the maximum xylanase activity measured at various experimental conditions. The conditions for optimal xylanase activity were assayed as follows. (1) $\mathrm{NaCl}$ concentrations $\left(0-22 \%, w / v\right.$, at intervals of $2 \%$ ) at $\mathrm{pH} 7.0$ and at $55^{\circ} \mathrm{C}$; (2) temperatures $\left(30-90{ }^{\circ} \mathrm{C}\right.$, at intervals of $5{ }^{\circ} \mathrm{C}$ ) with $4 \% \mathrm{NaCl}$ and $\mathrm{pH} 7.0$; and at $\mathrm{pH}(4.0-10.5$ with intervals of $0.5 \mathrm{pH}$ units) using sodium citrate buffer ( $\mathrm{pH} 4.0-6.0)$, sodium phosphate buffer ( $\mathrm{pH}$ 6.0-8.0), and glycine- $\mathrm{NaOH}$ buffer ( $\mathrm{pH} 8.0-10.5)$ at $4 \% \mathrm{NaCl}$ and at $55^{\circ} \mathrm{C}$. In addition, the effects of surfactants $(0.2 \%, v / v)$ and various metals $(5 \mathrm{mM})$ on xylanase activity were tested at optimal conditions (i.e., $4 \% \mathrm{NaCl}, \mathrm{pH} 7.0$, and $\left.55^{\circ} \mathrm{C}\right)$.

\subsection{Genome Sequencing, Annotation and Analysis Pipelines}

To obtain detailed genetic information of xylan degradation and saline-alkali tolerance, the whole genome of $A$. saponilacus was completely sequenced. Genomic DNA ( $5 \mu \mathrm{g})$ was extracted using Itop ${ }^{\mathrm{TM}}$ microbial DNA isolation kit (Itop, Beijing, China) according to the manufacturer's instructions (Beijing, China). After clone library construction, with a mean size of 8-10 kb using g-Tubes, genome sequencing was performed on a Pacific Biosciences RS II sequencer (Pacific Biosciences, Melon Park, CA, USA) using the SMRTbell temperate prep kit version 1.0 (Pacific Biosciences, Menlo Park, CA, USA) and loaded onto a single-molecule real-time (SMRT) cell (Pacific Biosciences, Menlo Park, CA, USA). All cleaned reads were de novo assembled using Hierarchical Genome Assembly Process (HGAP 2.0) [9], resulting in a single contiguous sequence. Briefly, single reads were mapped to seed reads, overlapping consensus sequences were created by a Celera assembler $8.0[10,11]$, and the remaining indel and base substitution errors were removed. This method can produce highly accurate and complete de novo assemblies for small prokaryotic genomes [12]. Additionally, libraries were constructed using the TruSeq Nano DNA library preparation kit (Illumina, San Diego, CA, USA) and used to generate 150-bp paired-end 
reads via the Illumina HiSeq 2000 platform (Illumina, San Diego, CA, USA). Remapping quality-filtered Illumina reads was performed by onto the assembly using BWA [13]. The alignment was passed to Pilon [14] to correct for indels and single nucleotide polymorphisms (SNPs). The average read length of the pacBio raw data was $\sim 6.6 \mathrm{~kb}$, with maximum read length of about 41,148 bases (coverage, $\sim 498$ ) and Illumina paired-end sequencing generated 1.1 million with $2 \times 150$-bp reads (coverage, $\sim 150$ ). The whole complete genome sequence of $A$. saponilacus SC $/ \mathrm{BZ}-\mathrm{SP} 2^{\mathrm{T}}$ has been deposited at DDBJ/ENA/GenBank under the accession number CP021904.

Glimmer 3.02 was used for gene prediction, gene number, gene total length, and so on [15]. Automated gene annotation was obtained though NCBI Prokaryotic Genome Annotation Pipeline (PGAP) [16]. Then, the genome files in GenBank format (gb file) were uploaded to the Integrated Microbial Genomes Expert Review (IMG/ER) tool [17] for functional annotation, followed the registration of IMG Analysis Project ID (Ga0265418), and Submission ID (184155) in the Genomes OnLine Database (Gold) [18]. Clusters of orthologous groups of proteins (COG) analyses were undertaken using COG functions and abundance profile analysis within IMG/ER [17]. Kyoto encyclopedia of genes and genomes (KEGG) pathway was analyzed using the online tool $[19,20]$.

\section{Results and Discussion}

\subsection{Characteristics of Alkalitalea saponilacus Xylanase}

Noticeably, A. saponilacus can use insoluble unsubstituted xylan as the sole substrate, indicating it can secrete extracellular xylanase into the surroundings [21]. This microorganism produces xylanase when using birch xylan, sucrose, maltose, glucose, and cellobiose as carbon sources [7]. Xylanase production with a mixture of $0.4 \%(w / v)$ sucrose and $0.1 \%(w / v)$ birch xylan substrates was 3.2 greater times than individual carbon sources of $0.5 \%(w / v)$ sucrose or $0.5 \%(w / v)$ birch xylan. This may reduce production costs of industrial xylanase because sucrose is widely distributed and less expensive [22]. Figure 1 shows the relative xylanase activity with respect to temperature of $30-90{ }^{\circ} \mathrm{C}$ (a broad optimum temperature of $45-55^{\circ} \mathrm{C}$ ), $\mathrm{NaCl}$ concentration of $0-22 \%(w / v)$ (a wide optimum range of $2-6 \%$ ), and $\mathrm{pH}$ of 4.0-10 (optimum pH 7.0). This xylanase tolerates high temperature, acidic and alkali conditions with its unique halophilic characteristic. Unfortunately, it is not alkaliphilic, which was unexpected based on previous descriptions. However, it is not uncommon because xylanase produced from alkaliphilic Bacillus sp. Strain K-1 also has an optimal activity at acidic pH 5.5 [21]. Xylanase activity tolerates surfactant $(0.2 \% v / v)$ such as Tween 20 and Triton X-100; its activity increased by 1.16 times with addition of Tween 20. In addition, activity is inhibited by $5-\mathrm{mM}$ metal ions of $\mathrm{Cu}^{2+}, \mathrm{Fe}^{3+}, \mathrm{Ni}^{2+}, \mathrm{Al}^{3+}$, $\mathrm{Mn}^{2+}, \mathrm{Co}^{2+}, \mathrm{Zn}^{2+}$, and $\mathrm{Ca}^{2+}$ with no influence from $\mathrm{Mg}^{2+}$.

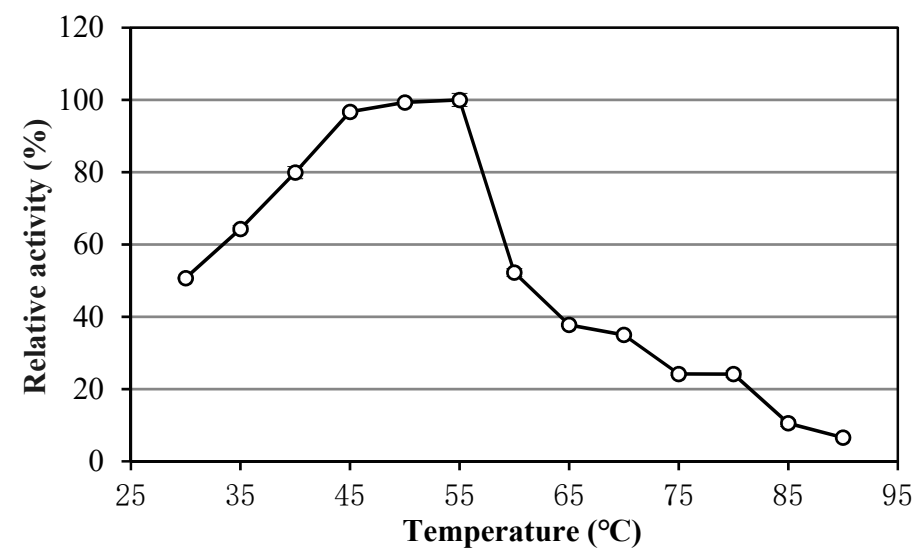

(A)

Figure 1. Cont. 


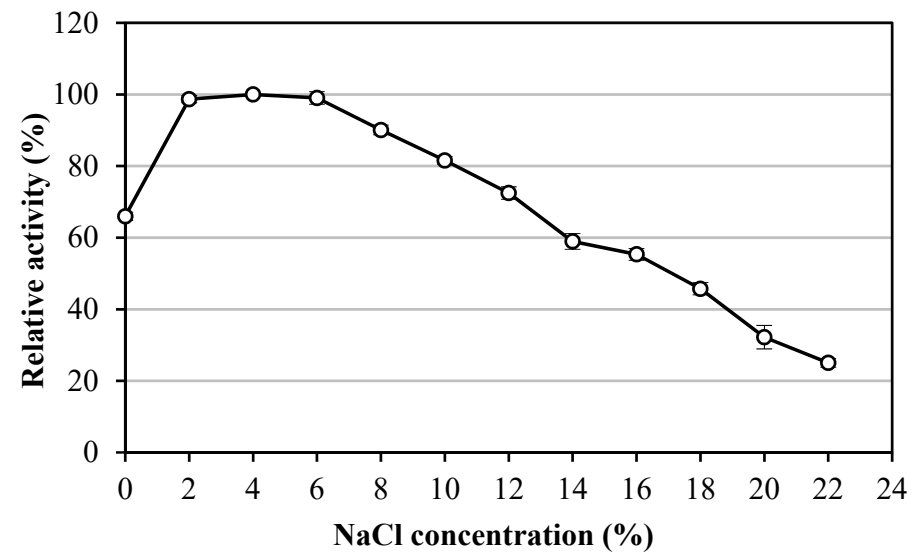

(B)

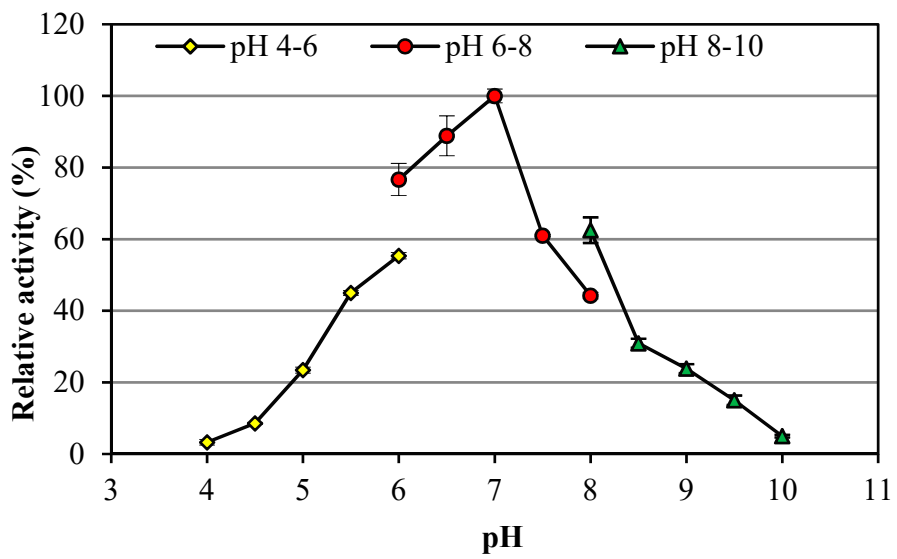

(C)

Figure 1. Characteristics of xylanase produced by Alkalitalea saponilacus. (A) Influence of temperature on xylanase activity, (B) Influence of different $\mathrm{NaCl}$ concentration on xylanase activity, (C) Influence of $\mathrm{pH}$ on xylanase activity. Buffer solutions are citric acid-sodium citrate buffer solution ( $\mathrm{pH} 4-6$ ), sodium hydrogen phosphate-sodium dihydrogen phosphate buffer solution ( $\mathrm{pH}$ 6-8), glycine-sodium hydroxide buffer solution ( $\mathrm{pH} 8-10)$, respectively. The error bars indicate standard deviation (SD) of triplicate determination.

\subsection{Genome Features of Alkalitalea saponilacus}

The complete genome of $A$. saponilacus contained only one chromosome with 4,775,573 bp. The genomic G+C content was $39.27 \%$ (Table S1 and Figure S1). Among the 3688 genes predicted, 3626 protein-coding genes (CDS) were predicted that accounted for $98.32 \%$ of the whole genome, and $74.02 \%$ of which (2684 CDS) were functionally annotated. Also, 12 rRNA genes (four $5 \mathrm{~S}$ RNAs, four 16S RNA, and four 23S RNA), 48 tRNA genes, and two noncoding RNAs (ncRNAs) were identified.

Of the total 3626 predicted protein-coding genes, 2225 genes $(60.33 \%$ of the total) were assigned to Clusters of Orthologous Groups (COGs) of proteins (Table S2) and distributed into 23 different categories. The cluster for "cell wall/membrane/envelope biogenesis (COG M)" (200, accounting for $8.99 \%$ COGs genes) was the largest group, followed by the classification of "carbohydrate transport and metabolism (COG G)" (181, 8.13\%), "translation, ribosomal structure and biogenesis (COG J)" $(178,8.00 \%)$ and "amino acid transport and metabolism (COG E)" $(159,7.15 \%)$. The categories 
of "extracellular structures (COG W)" (5, 0.22\%) and "cytoskeleton (COG Z)" (1, 0.04\%) were the smallest groups.

\subsection{The Identified Xylan-Degrading Related Enzymes in Alkalitalea saponilacus}

To completely degrade xylans with various substitutions, three major hydrolytic enzymes (endo- $\beta$-1,4-xylanases, $\beta$-xylosidases, and $\alpha$-glucuronidase) and several accessory enzymes (e.g., $\alpha$-L-arabinofuranosidases, $\alpha$-glucosidases uronidases, and acetyl and feruloyl esterases) might be necessary $[23,24]$. Genome analysis of $A$. saponilacus revealed one gene of endo- $\beta-1,4$-xylanase (XynA), six genes of $\beta$-xylosidase (GH43), one gene of $\alpha$-glucuronidase, and four genes of $\alpha$-L-arabinofuranosidase (Table 1). Absent were genes encoding acetylxylan esterase, ferulic acid esterase, and $p$-coumaric acid esterase. XynA, which belongs to glycoside hydrolase family 10 (GH10), is a crucial enzyme during xylan degradation and is responsible for fracturing the heteroxylan backbone [25]. XynA of A saponilacus shared the highest sequence identity (55.2\%) with the corresponding protein (RefSeq: WP_073173958) of Tangfeifania diversioriginum DSM 27063 ${ }^{\mathrm{T}}$, and was 52.4\% (WP_074935698) and 52.3\% (WP_013549140) identical to that of Algibacter lectus DSM $15365^{\mathrm{T}}$ and Cellulophaga algicola DSM $14237^{\mathrm{T}}$, respectively. Furthermore, a phylogenetic tree generated from amino acid sequences of 16 xylanase were constructed with neighbor-joining algorithms [26] in MEGA version 7 [27] (Figure 2). The phylogenetic tree showed XynA of $A$. saponilacus formed a single cluster with that of T. diversioriginum DSM $27063^{\mathrm{T}}$ (bootstrap support 76\%), and separate branch from those of both Algibacter lectus DSM $15365^{\mathrm{T}}$ and Cellulophaga algicola DSM $14237^{\mathrm{T}}$, suggesting XynA of A. saponilacus may possess distinct characteristics.

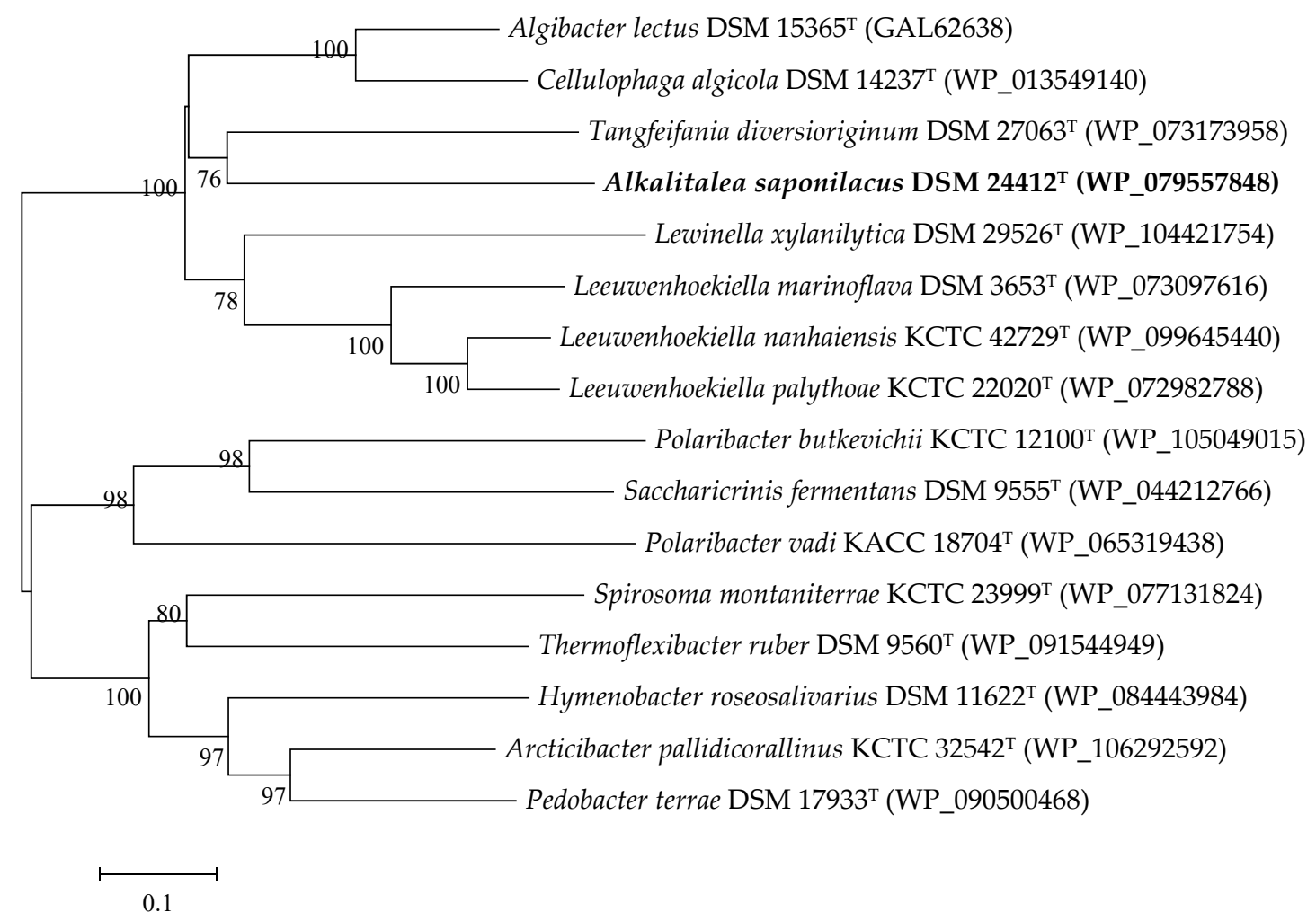

Figure 2. Neighbor-joining phylogenetic tree based on 16 xylanases sequences by using MEGA (Version 6). Numbers on nodes correspond to percentage bootstrap values for 1000 replicates. 
Table 1. The identified xylan-degradation-related enzymes. All locus tag numbers are predicted and indicated by IMG/ER. GH: glycoside hydrolase.

\begin{tabular}{ccc}
\hline Locus Tag & Product Name & GH \\
\hline CDL62_17705 & $\begin{array}{c}\text { Endo- } \beta \text {-1,4-xylanase } \\
(\text { XynA) } \\
\beta \text {-xylosidase }\end{array}$ & GH10 \\
CDL62_00085 & $\beta$-xylosidase & GH43 \\
CDL62_06240 & $\beta$-xylosidase & GH43 \\
CDL62_06275 & $\beta$-xylosidase & GH43 \\
CDL62_06380 & $\beta$-xylosidase & GH43 \\
CDL62_15875 & $\beta$-xylosidase & GH43 \\
CDL62_02285 & $\alpha$-glucuronidase & $\mathrm{GH67}$ \\
CDL62_00095 & $\alpha$-L-arabinofuranosidase & $\mathrm{GH} 43$ \\
CDL62_00195 & $\alpha$-L-arabinofuranosidase & $\mathrm{GH43}$ \\
CDL62_00495 & $\alpha$-L-arabinofuranosidase & $\mathrm{GH} 43$ \\
CDL62_12950 & $\alpha$-L-arabinofuranosidase & $\mathrm{GH} 51$ \\
CDL62_00395 & &
\end{tabular}

\subsection{The Predicted Xylan Degradation Pathways in Alkalitalea saponilacus}

To identify xylan degradation pathways in A. saponilacus, the 3688 annotated gene sequences to reference canonical pathways in KEGG were mapped and a total of 163 KEGG pathways were obtained. Based on KEGG annotation for genes of potential xylan-degrading enzymes (e.g., endo- $\beta$-1,4-xylanase and xylosidase), other potential enzymes involved in xylan degradation (e.g., xylose isomerase and D-xylulokinase) were also identified A. saponilacus (Figure 3). Using the genome sequence of A. saponilacus, these enzymes can be molecularly cloned to study their inherent characteristics and be modified through genetic engineering technology to be applied into industry.

Under the action of the above enzymes, XynA may possess a putative signal peptide containing 19 amino acids that can guide this enzyme to be secreted outside of cell. Thermotoga neapolitana, which was the highest identity sequence, has a similar extracellular enzyme that is secreted into the medium to degrade the macromolecular xylan to xylooligosaccharides, which are transported back into the cell through the specific oligosaccharide transport systems for further assimilation [25]. With the action of XynA, the glycosidic linkage $(\beta-1,4)$ of xylosides is broken first, and $\beta-1,4{ }^{-} \mathrm{D}^{-\mathrm{xy}} \mathrm{xlan}$ oligosaccharides form. Next, xylosidase removes xylose residues from the nonreducing end of $\beta-1,4-\mathrm{D}$-xylan oligosaccharides, leading to the release of D-xylose, which then converted into D-xylulose using xylose isomerase (XylA). After that, the phosphate and energy from hydrolysis of adenosine triphosphate (ATP) facilitates the conversion of D-xylulose to D-xylulose 5-phosphate, which then is used by the pentose phosphate pathway (PPP). Finally, the D-xylulose 5-phosphate may be transformed into propionic acid using other metabolic pathways [28]. Based on gene annotation, the above pathways are proposed as the way that xylan is metabolized by A. saponilacus. 


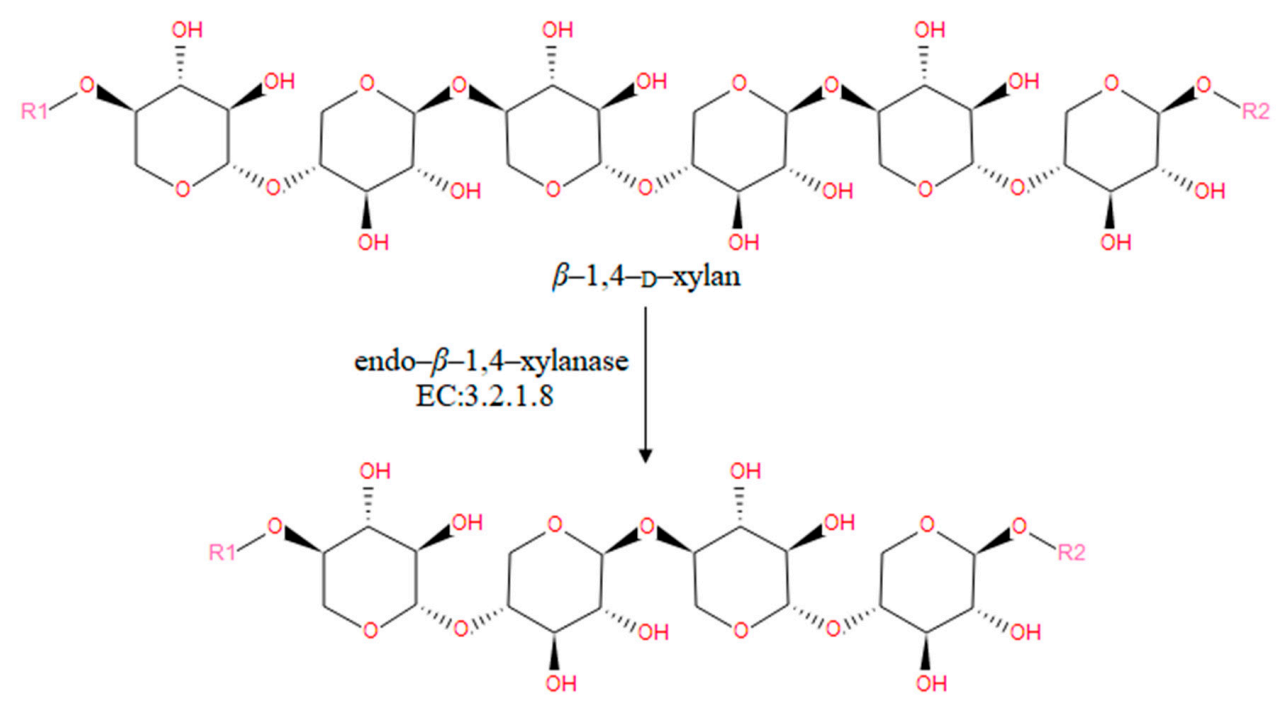

$\beta-1,4-\mathrm{D}-\mathrm{xylan}$ oligosaccharide

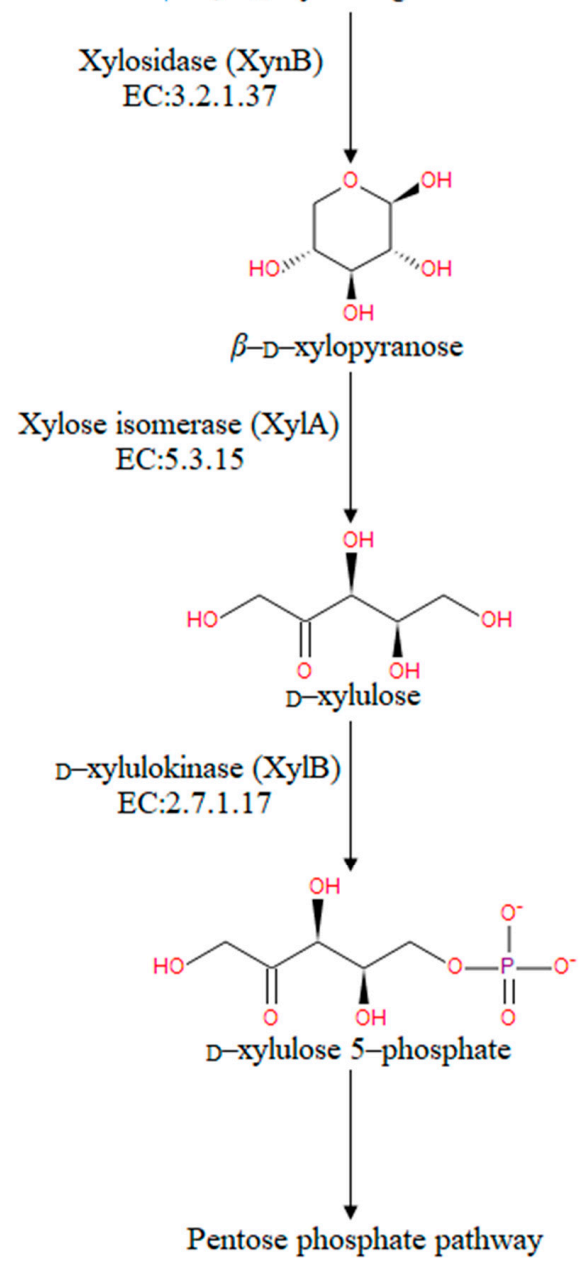

Figure 3. Enzymatic steps of xylan degradation pathways in A. saponilacus.

\subsection{The Genes Involved in Adaptation to Saline-Alkaline Conditions in Alkalitalea saponilacus}

Genome sequence analysis also showed that there are many genes that encode putative proteins potentially associated with the adaptation of $A$. saponilacus to saline-alkaline conditions (Table 2). The presence of $g \ln A$ gene encoding for L-glutamine synthase, one gene coding for choline/glycine/proline betaine transporter (BCCT family), and four genes for $\mathrm{Na}^{+} /$solute symporter 
(SSS family) indicates that $A$. saponilacus maintains osmotic equilibrium across membranes using the "compatible-solutes strategy" when exposed to high salinity [1,29-32]. Additionally, four genes affiliated with the Trk family (two-TrkA-type and two-TrkH-type) responsible for $\mathrm{K}^{+}$uptake systems were found, which implies that that $A$. saponilacus might achieve an isosmotic cytoplasm using $\mathrm{K}^{+}$ to cope rapidly with an osmotic shock [33]. To survive in highly alkaline conditions, A. saponilacus has developed genetic adaptations for $\mathrm{pH}$ homeostasis via the "influx of hydrogen ions" [34-36]; it harbors seven genes of multisubunit $\mathrm{Na}^{+} / \mathrm{H}^{+}$antiporter, four genes of monovalent cation $/ \mathrm{H}^{+}$ antiporter (CPA family, two-CPA1-type and two-CPA2-type), and one gene of $\mathrm{Na}^{+} / \mathrm{H}^{+}$antiporter (NhaC family). Eight genes encoding for $\mathrm{F}_{0} \mathrm{~F}_{1}$-ATP synthase and six genes coding for $\mathrm{H}^{+}$-transporting ATPase (V/A-type) allow A. saponilacus to maintain a constant hyper $\mathrm{pH}$ cytoplasm using proton gradients [37]. As described above, various predicted genes in $A$. saponilacus offer valuable insights to reveal the adaptive mechanisms of this haloalkaliphile.

Table 2. Genes in A. saponilacus involved in adaptation to saline-alkaline environments.

\begin{tabular}{|c|c|}
\hline Product Name & Locus Tag \\
\hline \multicolumn{2}{|l|}{ L-glutamine synthesis } \\
\hline L-glutamine synthetase, $\mathrm{G} \ln \mathrm{A}$ & CDL62_11360 \\
\hline \multicolumn{2}{|l|}{ Choline/glycine/proline betaine transporter (BCCT family) } \\
\hline \multicolumn{2}{|l|}{$\mathrm{Na}^{+} /$solute symporter } \\
\hline $\mathrm{Na}^{+}$/ solute symporter (SSS family) & CDL62_09935 \\
\hline $\mathrm{Na}^{+}$/ solute symporter (SSS family) & CDL62_06475 \\
\hline $\mathrm{Na}^{+} /$solute symporter (SSS family) & CDL62_14105 \\
\hline $\mathrm{Na}^{+}$/ solute symporter (SSS family) & CDL62_11075 \\
\hline \multicolumn{2}{|l|}{$\mathrm{K}^{+}$transport systems, potassium uptake protein (Trk family) } \\
\hline Trk system potassium uptake protein, TrkA & CDL62_03510 \\
\hline Trk system potassium uptake protein, $\mathrm{TrkH}$ & CDL62_03515 \\
\hline Trk system potassium uptake protein, TrkA & CDL62_03555 \\
\hline Trk system potassium uptake protein, $\mathrm{TrkH}$ & CDL62_12070 \\
\hline \multicolumn{2}{|l|}{$\mathrm{Na}^{+} / \mathrm{H}^{+}$antiporter (NhaC family) } \\
\hline $\mathrm{H}^{+} / \mathrm{Na}^{+}$antiporter (NhaC family) & CDL62_06020 \\
\hline \multicolumn{2}{|l|}{ Multisubunit $\mathrm{Na}^{+} / \mathrm{H}^{+}$antiporter } \\
\hline Multisubunit $\mathrm{Na}^{+} / \mathrm{H}^{+}$antiporter, MrpA subunit & CDL62_14320 \\
\hline Multisubunit $\mathrm{Na}^{+} / \mathrm{H}^{+}$antiporter, $\mathrm{MrpB}$ subunit & CDL62_14325 \\
\hline Multisubunit $\mathrm{Na}^{+} / \mathrm{H}^{+}$antiporter, MrpC subunit & CDL62_14330 \\
\hline Multisubunit $\mathrm{Na}^{+} / \mathrm{H}^{+}$antiporter, MrpD subunit & CDL62_14335 \\
\hline Multisubunit $\mathrm{Na}^{+} / \mathrm{H}^{+}$antiporter, MnhE subunit & CDL62_14340 \\
\hline Multisubunit $\mathrm{Na}^{+} / \mathrm{H}^{+}$antiporter, $\mathrm{MnhF}$ subunit & CDL62_14345 \\
\hline Multisubunit $\mathrm{Na}^{+} / \mathrm{H}^{+}$antiporter, MrpG subunit & CDL62_14350 \\
\hline \multicolumn{2}{|l|}{ Monovalent Cation $/ \mathrm{H}^{+}$antiporter (CPA family) } \\
\hline $\mathrm{K}^{+} / \mathrm{H}^{+}$antiporter (CPA1 family) & CDL62_09425 \\
\hline $\mathrm{K}^{+} / \mathrm{H}^{+}$antiporter (CPA1 family) & CDL62_00125 \\
\hline $\mathrm{Na}^{+} / \mathrm{H}^{+}$antiporter (CPA2 family) & CDL62_00920 \\
\hline $\mathrm{Na}^{+} / \mathrm{H}^{+}$antiporter (CPA2 family) & CDL62_05390 \\
\hline \multicolumn{2}{|l|}{$\mathrm{F}_{0} \mathrm{~F}_{1}-\mathrm{ATP}$ synthase } \\
\hline ATP synthase $F_{1}$ subcomplex gamma subunit, AtpG & CDL62_07555 \\
\hline ATP synthase $F_{1}$ subcomplex alpha subunit, AtpA & CDL62_07560 \\
\hline ATP synthase $F_{1}$ subcomplex delta subunit, AtpH & CDL62_07565 \\
\hline ATP synthase $F_{0}$ subcomplex B subunit, AtpF & CDL62_07570 \\
\hline ATP synthase $F_{0}$ subcomplex $C$ subunit, AtpE & CDL62_07575 \\
\hline ATP synthase $F_{0}$ subcomplex A subunit, AtpB & CDL62_07580 \\
\hline ATP synthase $F_{1}$ subcomplex epsilon subunit, AtpC & CDL62_07660 \\
\hline ATP synthase $\mathrm{F}_{1}$ subcomplex beta subunit, AtpD & CDL62_07665 \\
\hline \multicolumn{2}{|l|}{$\mathrm{H}^{+}$-transporting two-sector ATPase (V-type ATP synthase) } \\
\hline V/A-type $\mathrm{H}^{+}$-transporting ATPase subunit E, AtpE & CDL62_11640 \\
\hline V/A-type $\mathrm{H}^{+}$-transporting ATPase subunit A, AtpA & CDL62_11650 \\
\hline V/A-type $\mathrm{H}^{+}$-transporting ATPase subunit B, AtpB & CDL62_11655 \\
\hline V/A-type $\mathrm{H}^{+}$-transporting ATPase subunit D, AtpD & CDL62_11660 \\
\hline V/A-type $\mathrm{H}^{+}$-transporting ATPase subunit I, AtpI & CDL62_11665 \\
\hline V/A-type $\mathrm{H}^{+}$-transporting ATPase subunit K, AtpK & CDL62_11670 \\
\hline
\end{tabular}




\section{Conclusions}

This strain of A. saponilacus can grow anaerobically using xylan as the sole carbon source at hypersaline and extremely alkaline conditions. The xylanase activity with the combined substrates of $0.4 \%$ sucrose $+0.1 \%$ birch xylan substrates was significantly higher than with individual substrates of sucrose or birch xylan. Optimum xylanase activity was obtained at $2-6 \% \mathrm{NaCl}, \mathrm{pH} 7.0$, and $45-55 \mathrm{C}$. Xylanase activity increased by 1.16 times with addition of Tween 20 whereas it was inhibited by $5-\mathrm{mM} \mathrm{Cu}^{2+}, \mathrm{Fe}^{3+}, \mathrm{Ni}^{2+}, \mathrm{Al}^{3+}, \mathrm{Mn}^{2+}, \mathrm{Co}^{2+}, \mathrm{Zn}^{2+}$, and $\mathrm{Ca}^{2+}$. The genome sequence of $A$. saponilacus has revealed much about the many adaptations of this haloalkaliphile, which allows it to degrade xylan and live in extreme environments. The metabolic enzymes related to xylan degradation, particularly endo- $\beta-1,4$-xylanase (XynA), is a new resource of enormous potential value with halophilic characteristics. By synthesizing and transporting compatible solutes, A. saponilacus can maintain osmotic equilibrium and survive in hypersaline environments. The chromosome has a wealth of genes that allow $\mathrm{Na}^{+}, \mathrm{H}^{+}$, and $\mathrm{K}^{+}$to be imported and exported, which achieves an isosmotic cytoplasm that adapts to hypersaline environments.

Supplementary Materials: The following are available online at http:/ / www.mdpi.com/2073-4425/10/1/1/s1, Figure S1: Circular genome map of Alkalitalea saponilacus. The outermost ring of the circle indicates the size of genome, in which each scale represents $0.5 \mathrm{Mb}$. The second and third laps illustrate CDSs, colored by COG function classification. The second is forward strand, and the third is backward strand. The fourth circle denotes rRNA and tRNA. The fifth circle is GC content, the red part indicates that GC content is higher than average, whereas the blue is lower. The higher peak value heralds the greater difference in average GC content. The innermost circle states the $\mathrm{GC}$ skew $(\mathrm{G}-\mathrm{C} / \mathrm{G}+\mathrm{C})$. The plus-strand is more likely to transcribe CDS when the value is positive, yet minus strand tends to transcribe CDS when the value is negative; Table S1: Genome features of Alkalitalea saponilacus SC/BZ-SP2 ${ }^{\mathrm{T}}$; Table S2: Number of genes of Alkalitalea saponilacus associated with 23 general COG functional categories.

Author Contributions: Z.L. and B.Z. conceived, designed, collected data and analysis, and wrote the manuscript, M.H. designed and revised the draft paper, Y.Y. and H.W. performed in the sequence alignment and bioinformatics analysis, J.L. participated revised the draft paper. All authors reviewed the final draft.

Funding: This work was supported by grants 31370158 and 31570110 from the National Science Foundation of China (NSFC) and 1610042017001 from the Foundation of Graduate School of Chinese Academy of Agricultural Sciences (CAAS) to Baisuo Zhao.

Conflicts of Interest: The authors declare no conflicts of interest regarding this manuscript.

\section{References}

1. Zhao, B.; Yan, Y.; Chen, S. How could haloalkaliphilic microorganisms contribute to biotechnology? Can. J. Microbiol. 2014, 60, 717-727. [CrossRef] [PubMed]

2. Zhao, B.; Jun, L. Biodiversity of culture-dependent haloalkaliphilic microorganisms. Acta Microbiol. Sin. 2017, 57, 1409-1420.

3. De Graaff, M.; Bijmans, M.F.; Abbas, B.; Euverink, G.J.; Muyzer, G.; Janssen, A.J. Biological treatment of refinery spent caustics under halo-alkaline conditions. Bioresour. Technol. 2011, 102, 7257-7264. [CrossRef] [PubMed]

4. Jones, B.E.; Grant, W.D.; Duckworth, A.W.; Owenson, G.G. Microbial diversity of soda lakes. Extremophiles 1998, 2, 191-200. [CrossRef] [PubMed]

5. Bhatt, H.B.; Gohel, S.D.; Singh, S.P. Phylogeny, novel bacterial lineage and enzymatic potential of haloalkaliphilic bacteria from the saline coastal desert of Little Rann of Kutch, Gujarat, India. 3 Biotech 2018, 8, 53. [CrossRef] [PubMed]

6. Gohel, S.D.; Sharma, A.K.; Dangar, K.G.; Thakrar, F.J.; Singh, S.P. Biology and applications of halophilic and haloalkaliphilic actinobacteria. In Extremophiles from Biology to Biotechnology; Durvasula, R.V., Subba Rao, D.V., Eds.; CRC Press: Boca Raton, FL, USA, 2018.

7. Zhao, B.; Chen, S. Alkalitalea saponilacus gen. nov. sp. nov. an obligately anaerobic, alkaliphilic, xylanolytic bacterium from a meromictic soda lake. Int. J. Syst. Evol. Microbiol. 2012, 62, 2618-2623. [CrossRef] [PubMed] 
8. Zhao, X.; Luo, K.; Zhang, Y.; Zheng, Z.; Cai, Y.; Wen, B.; Cui, Z.; Wang, X. Improving the methane yield of maize straw: Focus on the effects of pretreatment with fungi and their secreted enzymes combined with sodium hydroxide. Bioresour. Technol. 2018, 250, 204-213. [CrossRef] [PubMed]

9. Chin, C.S.; Alexander, D.H.; Marks, P.; Klammer, A.A.; Drake, J.; Heiner, C.; Clum, A.; Copeland, A.; Huddleston, J.; Eichler, E.E.; et al. Nonhybrid, finished microbial genome assemblies from long-read SMRT sequencing data. Nat. Methods 2013, 10, 563-569. [CrossRef]

10. Koren, S.; Schatz, M.C.; Walenz, B.P.; Martin, J.; Howard, J.T.; Ganapathy, G.; Wang, Z.; Rasko, D.A.; McCombie, W.R.; Jarvis, E.D.; et al. Hybrid error correction and de novo assembly of single-molecule sequencing reads. Nat. Biotechnol. 2012, 30, 693-700. [CrossRef]

11. Myers, E.W.; Sutton, G.G.; Delcher, A.L.; Dew, I.M.; Fasulo, D.P.; Flanigan, M.J.; Kravitz, S.A.; Mobarry, C.M.; Reinert, K.H.; Remington, K.A.; et al. A whole-genome assembly of Drosophila. Science 2000, 287, 2196-2204. [CrossRef]

12. Roberts, R.J.; Carneiro, M.O.; Schatz, M.C. The advantages of SMRT sequencing. Genome Biol. 2013, 14, 405. [CrossRef] [PubMed]

13. Li, H.; Durbin, R. Fast and accurate long-read alignment with Burrows-Wheeler transform. Bioinformatics 2010, 26, 589-595. [CrossRef] [PubMed]

14. Walker, B.J.; Abeel, T.; Shea, T.; Priest, M.; Abouelliel, A.; Sakthikumar, S.; Cuomo, C.A.; Zeng, Q.; Wortman, J.; Young, S.K.; et al. Pilon: An integrated tool for comprehensive microbial variant detection and genome assembly improvement. PLoS ONE 2014, 9, e112963. [CrossRef] [PubMed]

15. Delcher, A.L.; Bratke, K.A.; Powers, E.C.; Salzberg, S.L. Identifying bacterial genes and endosymbiont DNA with Glimmer. Bioinformatics 2007, 23, 673-679. [CrossRef] [PubMed]

16. Tatusova, T.; DiCuccio, M.; Badretdin, A.; Chetvernin, V.; Nawrocki, E.P.; Zaslavsky, L.; Lomsadze, A.; Pruitt, K.D.; Borodovsky, M.; Ostell, J. NCBI prokaryotic genome annotation pipeline. Nucleic Acids Res. 2016, 44, 6614-6624. [CrossRef] [PubMed]

17. Markowitz, V.M.; Mavromatis, K.; Ivanova, N.N.; Chen, I.M; Chu, K.; Kyrpides, N.C. IMG ER: a system for microbial genome annotation expert review and curation. Bioinformatics 2009, 25, 2271-2278. [CrossRef] [PubMed]

18. Mukherjee, S.; Stamatis, D.; Bertsch, J.; Ovchinnikova, G.; Verezemska, O.; Isbandi, M.; Thomas, A.D.; Ali, R.; Sharma, K.; Kyrpides, N.C; et al. Genomes OnLine Database (GOLD) v.6: data updates and feature enhancements. Nucleic Acids Res. 2017, 45, D446-D456. [CrossRef] [PubMed]

19. Caspi, R.; Foerster, H.; Fulcher, C.A.; Kaipa, P.; Krummenacker, M.; Latendresse, M.; Paley, S.; Rhee, S.Y.; Shearer, A.G.; Tissier, C.; et al. The MetaCyc Database of metabolic pathways and enzymes and the BioCyc collection of Pathway/Genome Databases. Nucleic Acids Res. 2008, 36, D623-D631. [CrossRef]

20. Kanehisa, M.; Goto, S. KEGG: Kyoto encyclopedia of genes and genomes. Nucleic Acids Res. 2000, 28, 27-30. [CrossRef] [PubMed]

21. Ratanakhanokchai, K.; Kyu, K.L.; Tanticharoen, M. Purification and properties of a xylan-binding endoxylanase from alkaliphilic Bacillus sp. strain K-1. Appl. Environ. Microbiol. 1999, 65, 694-697.

22. Saleem, M.; Saleem, M.; Jamil, S. Production of xylanase on natural substrates Bacillus subtilis. Int. J. Agric. Biol. 2013, 2, 211-213.

23. Motta, F.L.; Andrade, C.C.P.; Santana, M.H.A. A review of xylanase production by the fermentation of xylan. classification, characterization and applications. In Sustainable Degradation of Lignocellulosic Biomass-Techniques, Applications and Commercialization; Chandel, A.K., da Silva, S.S., Eds.; INTECH: Chennai, India, 2013; pp. 251-275.

24. Saha, B.C. Purification and properties of an extracellular beta-xylosidase from newly isolated Fusarium proliferatum. Bioresour. Technol. 2003, 90, 33-38. [CrossRef]

25. Corral, O.L.; Villaseñor-Ortega, F. 14 Xylanases. In Advances in Agricultural and Food Biotechnology; Guevara-González, R.G., Torres-Pacheco, I., Eds.; Research Signpost: Kerala, India, 2006; pp. 305-322.

26. Saitou, N.; Nei, M. The neighbor-joining method: A new method for reconstructing phylogenetic trees. Mol. Biol. Evol. 1987, 4, 406-425.

27. Kumar, S.; Stecher, G.; Tamura, K. MEGA7: Molecular evolutionary genetics analysis version 7.0 for bigger datasets. Mol. Biol. Evol. 2016, 33, 1870-1874. [CrossRef]

28. Temudo, M.F.; Mato, T.; Kleerebezem, R.; van Loosdrecht, M.C. Xylose anaerobic conversion by open-mixed cultures. Appl. Microbiol. Biotechnol. 2009, 82, 231-239. [CrossRef] 
29. Huang, D.; Liu, J.; Qi, Y.; Yang, K.; Xu, Y.; Feng, L. Synergistic hydrolysis of xylan using novel xylanases, $\beta$-xylosidases, and an $\alpha$-L-arabinofuranosidase from Geobacillus thermodenitrificans NG80-2. Appl. Microbiol. Biotechnol. 2017, 101, 1-15. [CrossRef] [PubMed]

30. Banciu, H.L.; Sorokin, D.Y. Adaptation in haloalkaliphiles and natronophilic bacteria. In Polyextremophiles: Life Under Multiple Forms of Stress; Seckbach, J., Oren, A., Stan-Lotter, H., Eds.; Springer: Dordrecht, The Netherlands, 2013; pp. 121-178.

31. Banciu, H.L.; Muntyan, M.S. Adaptive strategies in the double extremophilic prokaryotes inhabiting soda lakes. Curr. Opin. Microbiol. 2015, 25, 73-79. [CrossRef] [PubMed]

32. Zhao, B.; Mesbah, N.M.; Dalin, E.; Goodwin, L.; Nolan, M.; Pitluck, S.; Chertkov, O.; Brettin, T.S.; Han, J.; Larimer, F.W.; et al. Complete genome sequence of the anaerobic, halophilic alkalithermophile Natranaerobius thermophilus JW/NM-WN-LF. J. Bacteriol. 2011, 193, 4023-4024. [CrossRef] [PubMed]

33. Roberts, M.F. Organic compatible solutes of halotolerant and halophilic microorganisms. Saline Syst. $2005,1,5$. [CrossRef]

34. Aono, R.; Ito, M.; Machida, T. Contribution of the cell wall component teichuronopeptide to $\mathrm{pH}$ homeostasis and alkaliphily in the alkaliphile Bacillus lentus C-125. J. Bacteriol. 1999, 181, 6600-6606.

35. Krulwich, T.A.; Sachs, G.; Padan, E. Molecular aspects of bacterial pH sensing and homeostasis. Nat. Rev. Microbiol. 2011, 9, 330-343. [CrossRef] [PubMed]

36. Slonczewski, J.L.; Fujisawa, M.; Dopson, M.; Krulwich, T.A. Cytoplasmic pH measurement and homeostasis in bacteria and archaea. Adv. Microb. Physiol. 2009, 55, 1-79. [PubMed]

37. Kochegarov, A.A. Modulators of ion-transporting ATPases. Expert Opin. Ther. Pat. 2001, 11, 825-859. [CrossRef]

(C) 2018 by the authors. Licensee MDPI, Basel, Switzerland. This article is an open access article distributed under the terms and conditions of the Creative Commons Attribution (CC BY) license (http:/ / creativecommons.org/licenses/by/4.0/). 